\title{
Improving content, organization, vocabulary, language use, and mechanics using Movie Trailer Media
}

\author{
Nehru Pasoloran Pongsapan ${ }^{1}$, Andi Anto Patak ${ }^{2}$ \\ ${ }^{1}$ Department of English Education, Faculty of Teacher Training and Education, Universitas Kristen Indonesia Toraja, \\ Makale, Indonesia \\ ${ }^{2}$ Department of English, Faculty of Languages and Literature, Universitas Negeri Makassar, Makassar, Indonesia
}

\begin{tabular}{l} 
Article Info \\
\hline Article history: \\
Received Oct 28, 2020 \\
Revised Mar 17, 2021 \\
Accepted Apr 12, 2021 \\
\hline
\end{tabular}

\section{Keywords:}

Language competence

Movie trailer

Students' writing skill

Teaching media

\begin{abstract}
Writing implicates conveying or communicating ideas or thoughts obliges the media either in conventional (paper and pen) or digital material (computer). This research applied a pre-experimental approach with one group pretest and post-test design. The independent variable is movie trailers as teaching media. The dependent variable is students' writing skills consist of content, organization, vocabulary, language use, and mechanics. This research indicated a significant difference in writing skills before and after the treatment using movie trailers with narrative text. There were 30 writing class students participated in this research; hence, they are homogeneous. Students seemed to be more encouraged to learn more about writing skills with enjoyable and relaxing strategies. This research signposted significant impact on the movie trailer's usage of writing skills' improvement. Movie trailers could be used as one of the learning media to foster students' resolution in telling stories in writing based on the imagination that comes after watching. Therefore, this research recommends using a movie trailer as one strategy to improve the students' writing ability.
\end{abstract}

This is an open access article under the CC BY-SA license.

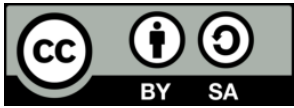

\section{Corresponding Author:}

Andi Anto Patak

Department of English, Faculty of Languages and Literature

Universitas Negeri Makassar

Makassar, South Sulawesi 90221, Indonesia

Email: andiantopatak@unm.ac.id

\section{INTRODUCTION}

Language is a means of communication, which is produced in speaking and writing, and it is acquired in listening and reading. By speaking and writing, human beings can argue thoughts, wishes, desires, notions, and emotions to influence others [1]. Through language, humankind can express feelings and connect imagination to think creatively about something new [1], [2]. Language serves as a tool for a community to deliver messages to the community or others. Therefore, the language is used to communicate well, either in spoken or written form, should be in sentences to convey useful meaning [3].

Unlike speaking, writing involves transferring or expressing ideas or thoughts that require the media for writing either in conventional (paper and pen) or digital material (computer). Writing is a series of processes, starting from thinking about the idea conveyed to the reader to determine how to disclose or present the words in sentences and paragraphs [4]. Students in learning writing often experience some common difficulties [5], [6] requiring the teachers' effective method. Students often find difficulty in expressing ideas in excellent or structured sentences to be arranged in paragraphs. The teacher-centered 
method's typical use results in one-way communication [7]-[9]— unavailability of attractive media for learning discouraged students from learning writing creatively.

Therefore, as the central part of formal education, the teacher demands to arrange creative and innovative teaching methods, especially in the teaching and learning process [10]. Thus, learning, especially for writing, can be useful and optimal. Teachers can educate students to become capable writers. Therefore, the teachers should prepare the students to compose or coordinate ideas or thoughts into sentence sequences, which are logical and integrated into a written language [11]-[13]. By having writing competence, a student can express or inform others' richness of her/his thoughts, feelings, experiences, and imagination.

Writing is one of the productive skills (writing and speaking) is required for students alongside receptive skills (listening and reading). Early knowledge of communicative gestures is an essential part of early productive language development [14], [15]. Teaching should be continuous by involving more practical activities to meet the needs of learners. Further enabling students' productive skills should be one of the teacher's primary goals and motivations [16]. Students need to learn writing to enhance their ability to express ideas, opinions, and feelings in written form [17]. Teachers should help students to be skilled in writing. Students can be mediated to reinforce their grammatical structures, idioms, and vocabulary through writing training.

Writing includes a cognitive process of discovering meaning [5], [18]. The process advises the teaching of composition to recognize generating, formulating, and refining ideas. The writing instruction should prioritize the revision that writing teachers can be a mediator during the process, and students can be excellent in writing skills. Writing is considered difficult for English as a Foreign Language (EFL) students [19], [20] because it is not used as a formal language [21]. Writing skills are proficiencies that relieve students to express their beliefs in a meaningful sentence before interacting with the message. It is hard to set up word for word to become a sentence and a sentence to become a paragraph afterward organized the coherent and cohesive writing [22], [23]. Writing skill is complex and challenging to learn. Writing is not merely about grammatical patterns, but it covers an organization of progressive ideas and information [24], [25]. Writing is also about appropriating suitable vocabularies and word styles to create good sentence structure [22], [25].

Enhancing the students' writing ability, teachers have used many teaching methods and strategies. However, numerous students still lack the competence to convey their ideas in English written form. Hence, the researchers are interested in implementing movie trailer media in teaching students effective and enjoyable writing. Moreover, movie or film shows a unique communication medium and teaching resource [26]. The movie media appeals to students because many media themes to be chosen and developed. Students are expected to gain valuable experience and increase their writing skills using the movie in teaching and learning tools. Media, especially in industrial revolution 4.0, could help the learning process more straightforward and turn on target [27]. They consent students to recognize the substance of whatever is being taught [28]. Media can correspondingly relieve learning and concern in the language course that endows an inspiring drive [29]. The reason for choosing the movie trailer is that it is a shorter duration than a full movie. Moreover, the movie trailer represents the whole scene of the full movie.

Movie trailer strives for attracting the watchers to watch the full scenes [30]. The trailer is extracted from the film's best sensational, comical, or different remarkable fragments [31]. These parts are in a shortened form and typically deprived of generating spoilers. Thus, the scenes on trailers are unnecessarily in the order as they appear in the full version [32]. A trailer is designed to be displayed, which is no more extended than two minutes and thirty seconds. Movie trailer media is attractive and more straightforward than a full movie. It is considered attractive for students to watch the trailer because it covers the whole scene. Moreover, the researcher used animated, funny, and exciting movie trailers. The length was shorter than a full movie so that students never get bored watching the movie trailer, and students are expected to be more interested in learning English mainly to write a narrative text. Ultimately, it is expected that using a movie trailer can challenge students to write narrative text using narrative analysis.

\section{RESEARCH METHOD}

\subsection{Design}

The researcher used a pre-experimental approach with one group pretest and post-test design [33]. This research's independent variable is the movie trailer as a teaching medium that shows the movie's main idea. This strategy is supposed to enable students in narrative text writing. In the narrative analysis, teachers tell their own story; in this case, the researchers were deciding the movie trailer in our way and decide how to find an adequate method to gather and analyze the data [34] in the sense of narrative ethics [35]. The dependent variable is students' writing skills consist of content, organization, vocabulary, language use, and mechanics. Content encompasses the writing body, and the organization comprises organizing materials in 
writing. Vocabulary deals with putting words into a sentence and putting the sentence into a paragraph. Language use in this research concerns the appropriate use of grammar and structure. Mechanic deals with pronunciation, spelling, and punctuation.

\subsection{Participants}

There were 30 writing class students participated in this research. Therefore, they are homogeneous. This research implemented a writing test to determine the students' writing skills based on the narrative text's topics. The researchers conducted the pretest at the beginning of this study. In this part, the researchers assigned the students to make a narrative text related to the topic. The post-test followed the treatment using movie trailers.

\subsection{Treatment}

In the treatment, the students were given three worksheets guiding them to compose a story. They are expected to write a story related to the movie trailer given. The students were supposed to write a narrative story using the common organization consisting of orientation, problem, and resolution at the end of the treatment [34]. The first worksheet deals with an exposure that leads students to find out the movie trailer's characters. The second worksheet concerns the problems of the character's action in the movie trailer. The third worksheet assigned the students to write a story on the movie trailer related to the first and second worksheets. This narrative text was written by considering five writing elements: content, organization, vocabulary, language use, and mechanics using writing assessment [36]. A post-test was given after conducting treatment. It aimed to find out the significance of the treatment.

\section{RESULTS}

After conducting pretest, treatment, and post-test, the researchers analyzed the mean score and the standard deviation. This research is in experimental design; the researchers describe the mean score and standard deviation before and after conducting treatment to examine any improvement. The higher the mean score and the lower the standard deviation indicate the experimental research [37]. The mean score and standard deviation in this study are presented in the form of Paired Sample Statistics that is shown in Table 1.

Table 1. Paired sample statistics

\begin{tabular}{lccccc}
\hline & & Mean & N & Std. Deviation & Std. Error mean \\
\hline Pair 1 & Pretest & 11.20 & 30 & 3.95 & 0.72 \\
& Posttest & 15.60 & 30 & 3.06 & 0.56 \\
\hline
\end{tabular}

Table 1 shows that the Mean score on training or treatment of writing skills using movie trailer media with the narrative text approach got more scores (15.60) in the post-test than in the pretest (11.20). The Standard deviation also shows that the pretest's spread in the pretest is somewhat more extensive than that in the post-test. These differences seem to be supporting the hypothesis in this research. However, to determine whether this result is significant, the Paired Samples Test must be examined [37]. The paired sample test is shown in Table 2.

Table 2. Paired samples test

\begin{tabular}{|c|c|c|c|c|c|c|c|c|c|}
\hline \multicolumn{10}{|c|}{ Paired differences } \\
\hline & & \multirow[t]{2}{*}{ Mean } & \multirow[t]{2}{*}{ SD } & \multirow{2}{*}{$\begin{array}{l}\text { Std. Error } \\
\text { mean }\end{array}$} & \multicolumn{2}{|c|}{$\begin{array}{l}95 \% \text { Confidence interval } \\
\text { of the difference }\end{array}$} & \multirow[t]{2}{*}{$\mathrm{t}$} & \multirow[t]{2}{*}{ df } & \multirow[t]{2}{*}{$\begin{array}{c}\text { Sig. } \\
\text { (2-tailed) }\end{array}$} \\
\hline & & & & & Lower & Upper & & & \\
\hline Pair 1 & Pretest-Posttest & -4.40 & 1.97 & 0.36 & -5.14 & -3.66 & -12.23 & 29 & .000 \\
\hline
\end{tabular}

Table 2 indicates that test statistic $(t=-12.23)$, degrees of freedom $(\mathrm{df}=29)$, and probability value $(p=<0.001)$. Thus, this research shows $t(29)=-12.23 ; p<0.001$. The mean in Table 2 shows the difference between the pretest and post-test means $(11.20-15.60=-4.40)$. The mean difference of -4.40 which is much smaller than the standard error of the mean of 0.36, suggesting that the data support the null hypothesis in this research that there is a significant difference in writing skill before and after using the movie trailers media in writing narrative text. 
Students seemed to be more motivated to learn more about writing skills from the method that they experience enjoyable and relaxing. Students showed the awareness to accomplish the task given. Thus, this research supports the research by Stepanek [38] that a creative approach to language teaching comprises a method to be aware and raise students' value in the classroom. The students writing skill assessed in this research is classified into five competencies: content, organization, vocabulary, language use, and mechanics [36].

\subsection{Content}

Figure 1 shows a significant improvement in the content aspect. Classifying the students' score based on content is noticeably apparent that three classification scores improved considerably. These three classifications are "college-level work", "unacceptable-not", and "excellent to good". Figure 1 shows a significant increase in "college-level work" (29\%) and "unacceptable-not" (25\%) on pretest to $2 \%$ in the post-test, respectively. The "excellent to good" classification also improved significantly from $2 \%$ at pretest to $29 \%$ at post-test.

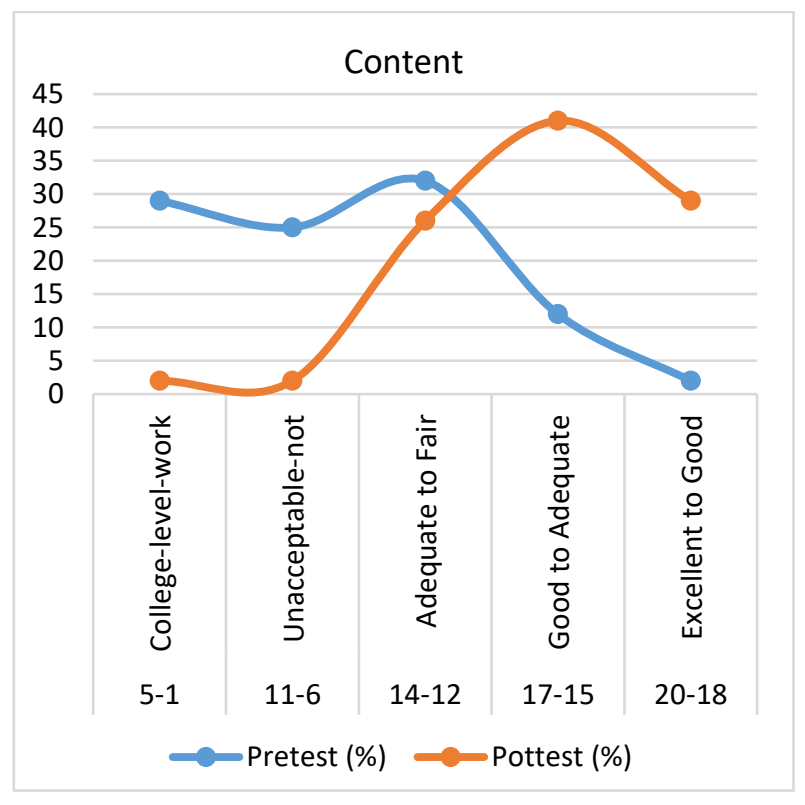

Figure 1. Content competence

Thus, the majority of the participants $(96 \%)$ were within the level of "adequate to fair", "good to adequate", and "excellent to good". Consequently, only $4 \%$ of the participants remained within the collegelevel-work level and unacceptable-not in the post-test.

\subsection{Organization}

Figure 2 shows that there was a significant increase in the ability of students in organizational competence. On the pretest, only $18 \%$ of students were in good to adequate level until excellent to good. Whereas in post-test, there was a significant improvement to $69 \%$. Figure 2 shows that the highest percentage of students in the pretest was at the level of adequate to fair, which was 39\%. The highest percentage of students at the post-test was at a good to a proper $48 \%$ level. Overall, $82 \%$ of the students ranging from the college-level-work, unacceptable-not, to adequate to fair at the time of pretest. While at the time of the posttest, $96 \%$ of students were from the level of adequate to fair, good to adequate, and excellent to good. Thus, only $4 \%$ of the students were categorized within the college-level-work and unacceptable-not. 


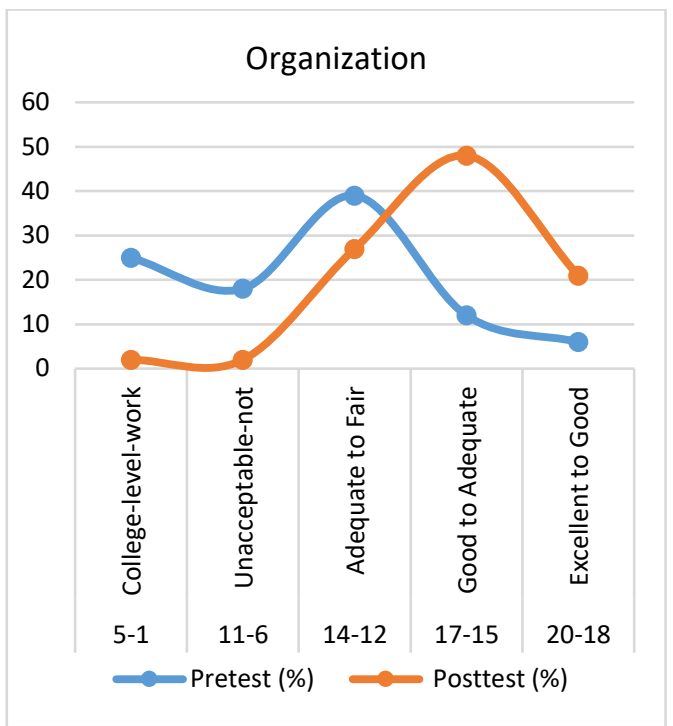

Figure 2. Organization competence

\subsection{Vocabulary}

Figure 3 shows an increase in the competence of vocabulary. The percentage at each level of vocabulary competence increased considerably - students whose vocabulary competence at the lowest level indicates a significant improvement in the post-test. The details of the vocabulary competence improvement in this research are presented in Figure 3.

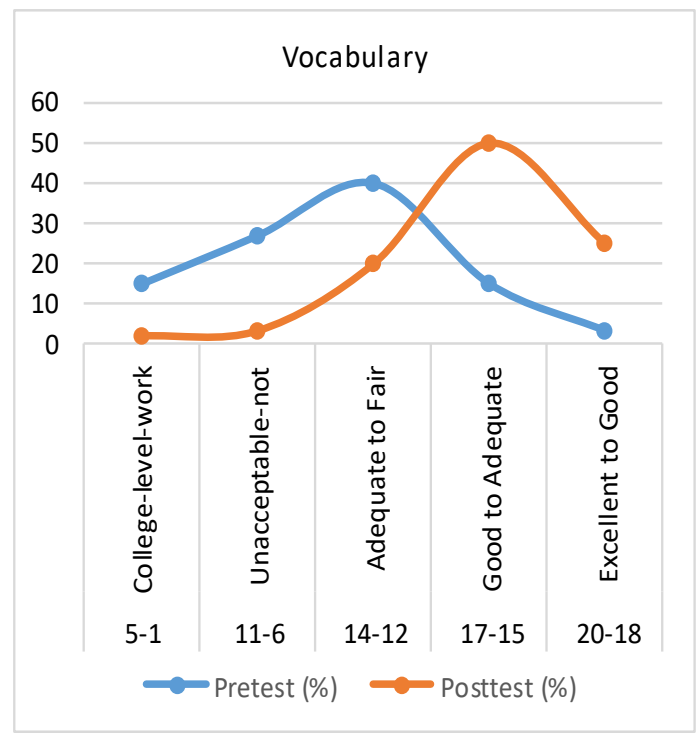

Figure 3. Vocabulary competence

Figure 3 shows students with the lowest ability or college-level-work as much as $15 \%$ in the pretest. This percentage decreased to $2 \%$ in the post-test, indicating a significant increase in vocabulary competence. Level of unacceptable-not also shows a considerable improvement in vocabulary competence from $27 \%$ in pretest to $3 \%$ in the post-test. The percentage of students at the adequate to fair level decreased from $40 \%$ to $20 \%$ due to the significant increase in good to adequate and excellent to good level. Thus, the total percentage of good to adequate and excellent to good was $75 \%$, indicating the considerable improvement in students' vocabulary competence.

Int J Eval \& Res Educ, Vol. 10, No. 2, June 2021: 728 - 737 


\subsection{Language use}

Figure 4 indicates that the highest pretest percentage was at the lowest level in language use competence. There were $41 \%$ of students were still at the college-level-work level at the pretest. At the same time, none of the students were at the excellent to good level in the pretest. The gap between these significance levels is presented in Figure 4.

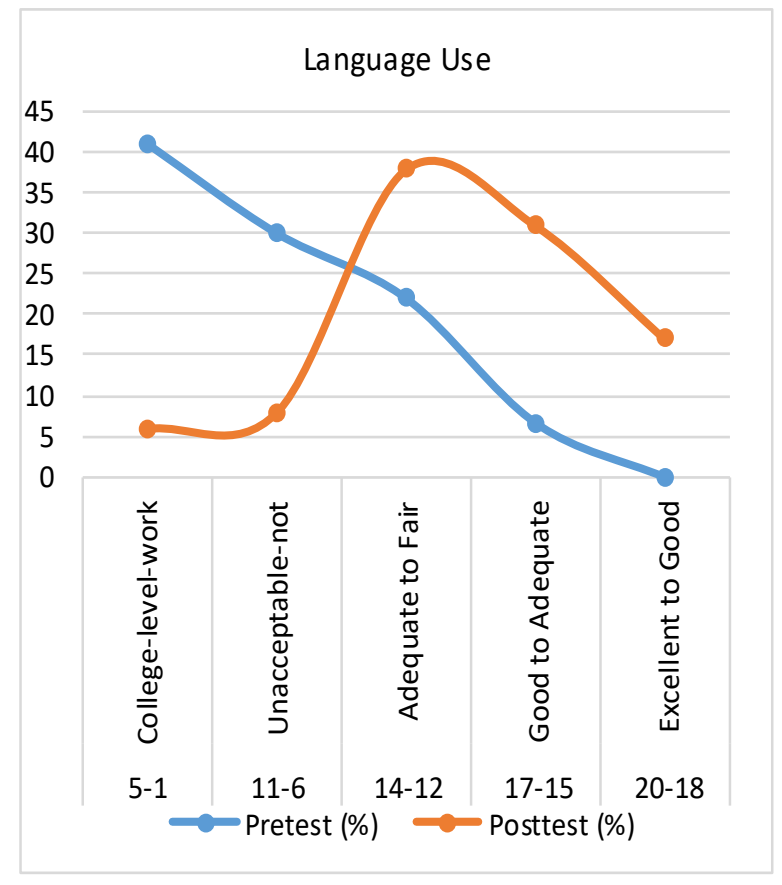

Figure 4. Language use competence

In Figure 4, the highest percentage $(41 \%)$ of the pretest is at the lowest level in language use competence; however, only $6 \%$ of the students were at this post-test level. None of the students were at the excellent to good level in the pretest, but $17 \%$ achieved excellent to good in the post-test. The unacceptablenot level, which was $30 \%$ in the pretest, remained only $8 \%$ in the post-test. It seems that the increasing percentage of adequate to fair level from $22 \%$ in the pretest to 38 in post-test due to the students' competence level on language use increased to a higher level. Good to adequate level shows the significant improvement level from $7 \%$ at pretest to be $31 \%$ at the post-test.

\subsection{Mechanics}

Figure 5 indicates that students seemed to perceived the mechanics as difficult competence in writing skill. On the one hand, half of the students were in the level of college-level-work and unacceptablenot. On the other hand, only $2 \%$ of students were in the excellent to good level and only $5 \%$ in the pretest's good to adequate level. However, Figure 5 shows a significant increase in the mechanic's competence of the students.

The most significant improvement of the classification score was good to adequate; this level improved from $5 \%$ in the pretest to $48 \%$ in the post-test. This research indicates that half of the students were in college-level-work and unacceptable-not in the pretest, but improved considerably to be half of the total participants in the level of good to adequate and excellent to good in the post-test. Besides, only $3 \%$ of the students were still in college-level-work and $9 \%$ in the unacceptable-not in the post-test. Ultimately, students' competence in Mechanics improved considerably after the treatment. 


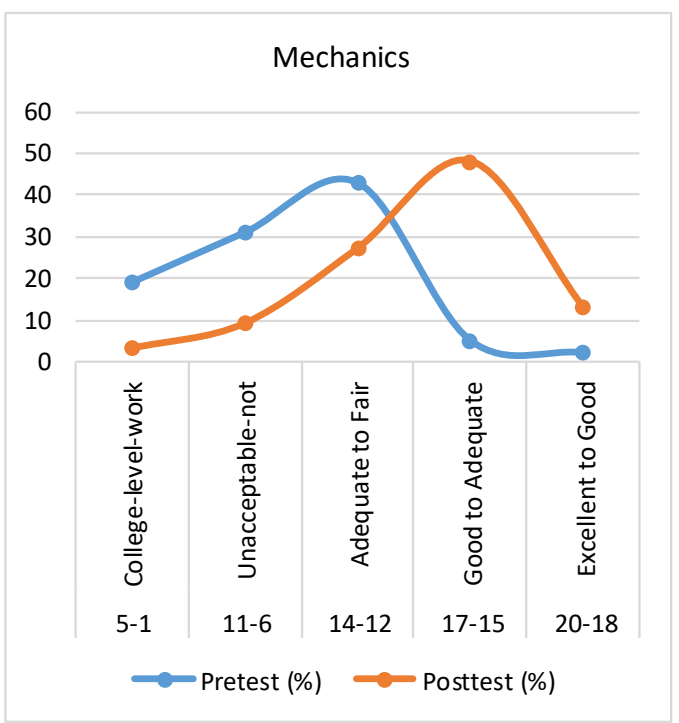

Figure 5. Mechanics competence

\section{DISCUSSION}

Before the treatment was applied, all the students were lack of five elements assessed in this research; they are content, organization, vocabulary, language use, mechanics. The pretest was given at the beginning of this research to identify the students' competency in writing. The pretest consists of two topics: the students were required to choose one of them to make a story. After conducting pretest, several problems in writing components were found by the researchers. These problems were limited in content, organization vocabulary, language use, and mechanics using writing assessment [36].

Because of the problems, the researchers gave the students treatment to improve their writing competence by using movie trailers. The researchers applied four meetings on treatment. The movie trailer's topics were different from each meeting. The movie trailer was initially shown, and then the students were given three worksheets in every treatment.

During the treatment, some benefits got by the students. Movie trailers mediate students to benefit because they listen to the language, but they can watch it simultaneously. Implementing a digital video can help students in language learning [39]. Students could guest general meaning through expression and gestures showed by the characters in the movie trailers. Thus, students could observe how intonation can match facial expressions. All such features gave valuable meaning clues and helped students to find out beyond what they are listening. Thus, the interpretation of the characters in the movie trailers is more comprehensible.

Moreover, in this research, the students acquired some effects from the movie trailers. They listened to the language, watched the video, and perceived characteristics of the movie trailer. This procedure is expected to help the students compose a story as they listen and watch. By practicing this method, students can be accustomed to writing skills and other skills, such as listening, speaking, and reading. Movie trailers in the commercial form also display the critical script as subtitles required translation and interpretation [40]. Thus, the four language skills are integrated.

However, writing skill is emphasized in this research due to its vital function in written communication. Through writing, people can convey ideas or feelings of pleasure, sadness, disappointment, despair, surrender, or anything else. Writing can represent the part of writing as the representation or part of the language expression unit [41]. However, expressing feelings through writing is not as easy as we imagine.

Anxiety comprises the number one obstacle in writing. The anxiety can discourage people from looking at the blank paper or computer screen to start expressing ideas [42]-[44]. Sometimes, it is easy to convey ideas in spoken form, but it always difficult to express them in written form. Writing is often viewed as an uncomfortable activity and many other negative reasons. Therefore, efficient, enjoyable, and comfortable writing should be introduced to students. It is expected to encourage them to write effectively and efficiently since writing is a productive and expressive activity. Moreover, writing as one of the English subject skills in secondary school requires learners to organize their thoughts, ideas, and feelings in written form. Learning to write at formal education prepares learners to write based on the basic rules of writing. 
Indeed, it is extremely difficult or even horrible to assign students to write without a specific method to motivate them to start writing. Sometimes teachers find it challenging to decide the learning resource for teaching writing. Nowadays, it is not difficult finding out teaching resources. They are around us; one of them is a movie trailer. Moreover, widespread internet access enables the teacher to search for millions of teaching resources [45].

\subsection{The movie is appropriate for learning purposes}

Good movies are everywhere; they can easily be found on YouTube and other learning websites [45]. The task of teachers to provide quality movies as a means of teaching with creativity. Watching movie trailers is one way to make students understand a concept or get more than the teacher informed in the classroom. Using movie trailers as a learning tool is not an idea that comes suddenly; it should be wellplanned. It is vitally important for teachers to consider a suitable movie with suitable teaching materials. The movie trailer that teachers use in the class should be appropriate, and the scenes are within the context of teaching materials.

To achieve optimal learning objectives requires the use of media as tools or resources in the learning process. The movie is beneficial for teachers to attain the effectiveness of learning, especially in productive skills. The use of learning media, such as movie trailers, can also maximize learning objectives. Exciting learning media is also indeed expected to stimulate the interest of learners to learn more independently. Learners become active and motivated to practice the exercises because they can watch the movie trailers at home since the material is in an mp4 format. Moreover, students can discuss or ask for an explanation from their classmates. Using movie trailers in teaching writing is one of the demands of the advanced digital era.

The movie is included in the category of motion media with some advantages over other educational media such as print media. The advantages contained in the movie video cause the appropriate movie is used for learning purposes, as multimedia elements. The movie is a teaching medium that is memorable enough to be used in learning because it incorporates multimedia elements such as audio, visual, motion, color, and three-dimensional impression. The excess movie, in which the use of motion elements, sounds, colors, and light into a movie can directly attract students' interest and encourage student learning. The dramatic elements and activities in the movie attempt can enhance the impression of teaching and learning.

Moreover, teachers can use the movie as media to manipulate space perspective, time, and size. The use of movie can set up space; different views can represent a phenomenon. For example, students are shown visually how a mosquito sucks human blood firmly. The movie has the advantage of manipulating the period, in which teachers can make changes to the time by using techniques such as slow-motion, fast motion, frame by frame, and absorption. The movie also compresses, accelerates, or stretches the period with absorption or darkening techniques. In real life, many things take a long time to understand. For example, it is complicated to understand the construction of a bridge or skyscrapers. Both bridge and skyscrapers construction can be demonstrated through the movie, and students can learn about these processes quickly.

\subsection{The movie is media communication for educational messages}

As media communication, the movie can be used for delivering a lesson. The movie can help teachers convey in detail and real educational messages such as the curriculum's learning content and the formation of student attitudes and behavior [46], [47]. The movie is considered a pedagogical tool [48]. Also, the movie can be used to highlight life's religiosity and evoke emotions and feelings. The movie is seen as a dynamic medium that can stimulate internal and external feedback that sometimes affects a person's psychology. The movie can be used to convey educational messages related to the leader's moral and leadership attitudes. This is vitally important to avoid the media's adverse effect [49].

Movies can help teachers explain something abstract or difficult to explain. Movies can bring the real problem into the same place as things that have passed or are happening without time, distance, and place. Movies can improve students' understanding, avoid misinterpretation, and facilitate learning. Movie in the form of drama, documentation, entertainment ads is beneficial to achieve specific teaching objectives. For example, Drama can be used for changes in attitude, views, and emotions or as a media for persuasive effectiveness [50]. Advertising can be exploited to plant real values [51]; the documentary movie can be used for society's famous world and culture [52]. A movie can be repeatedly viewed and viewed many times to help improve memory and proficiency.

\section{CONCLUSION}

This research indicated a significant influence on the use of movie trailers to improve writing skills. Movie trailers media can foster students' resolution in telling stories in writing based on the imagination that comes after watching. English teachers are expected to implement a movie trailer as one of the strategies to 
improve the students' writing ability. The researchers suggest the English teacher choose an animated, exciting, and funny movie trailer to make the students interested in watching. The teacher should set up a good relationship with all the students. A good atmosphere in the classroom reinforces the students' motivation to be successful in their learning. It is recommended for future research on movie trailers use to prepare a list of vocabulary throughout the treatments to enable students to answer the question.

\section{ACKNOWLEDGEMENTS}

This research is fully funded by Universitas Kristen Toraja, Tana Toraja, South Sulawesi, Indonesia with contract number: 01/LPPM-UKIT/ST-P/V/2019.

\section{REFERENCES}

[1] D. Bickerton, Language and human behavior. University of Washington Press, 2017.

[2] U. L. Mishina and I. Iskandar, "The Role of English Language in Nigerian Development," GNOSI An Interdiscip. J. Hum. Theory Prax., vol. 2, no. 2, pp. 47-54, 2019.

[3] G. N. Leech, Principles of pragmatics. Routledge, 2016.

[4] F. Cangià, "Written emotional disclosure and boundary making. Minority children writing about discrimination," Multicult. Educ. Rev., vol. 6, no. 2, pp. 25-52, 2014.

[5] L. W. Gregg and E. R. Steinberg, Cognitive processes in writing. Routledge, 2016.

[6] D. Brande, Becoming a writer. Lulu, 2016. [Online]. Available: https://www.lulu.com.

[7] E. Consuegra and N. Engels, "Effects of professional development on teachers' gendered feedback patterns, students' misbehaviour and students' sense of equity: results from a one-year quasi-experimental study," Br. Educ. Res. J., vol. 42, no. 5, pp. 802-825, 2016.

[8] A. Hatun Ataş and Ö. Delialioğlu, "A question-answer system for mobile devices in lecture-based instruction: a qualitative analysis of student engagement and learning," Interact. Learn. Environ., vol. 26, no. 1, pp. 75-90, 2018.

[9] M. C. M. de Guerrero and O. Villamil, "Metaphor analysis in L2 education," Elicited Metaphor Anal. Educ. Discourse, vol. 3, p. 93, 2015.

[10] J. C. Richards and T. S. Rodgers, Approaches and methods in language teaching. Cambridge University Press, 2014.

[11] A. A. Patak and M. Tahir, "Avoiding plagiarism using Mendeley in Indonesian higher education setting," Int. J. Eval. Res. Educ. (IJERE), vol. 8, no. 4, pp. 686-692, 2019, doi: 10.11591/ijere.v8i4.20268.

[12] A. A. Patak, "The influence of online learning environment, lecturers' assessment practice, and students' writing skills on students' plagiarism practices," Universiti Teknologi Malaysia, 2018.

[13] S. Sumarni, M. M. Fauzan, S. A. M. Mofreh, and A. A. Patak, "Investigating students' reflection toward selfassessment on creative writing achievement in ESP course," Int. J. Humanit. Innov., vol. 1, no. 1, pp. 8-16, Mar. 2018, doi: 10.33750/ijhi.v1i1.3.

[14] A. Sundqvist, E. Nordqvist, F. S. Koch, and M. Heimann, "Early declarative memory predicts productive language: A longitudinal study of deferred imitation and communication at 9 and $16 \hat{\mathrm{A}}$ months," J. Exp. Child Psychol., vol. 151, pp. 109-119, 2016, doi: 10.1016/j.jecp.2016.01.015.

[15] A. Abduh and R. Rosmaladewi, "Language Policy, Identity, and Bilingual Education in Indonesia: A Historical Overview," XLinguae, vol. 12, no. 1, pp. 219-227, 2019.

[16] D. Golkova and S. Hubackova, "Productive Skills in Second Language Learning," Procedia - Soc. Behav. Sci., vol. 143, pp. 477-481, 2014, doi: 10.1016/j.sbspro.2014.07.520.

[17] M. Maru, S. Nur, and F. Lengkoan, "Applying video for writing descriptive text in senior high school in the Covid19 pandemic transition," Int. J. Lang. Educ., vol. 4, no. 3, pp. 408-419, 2020, doi: 10.26858/ijole.v4i3.14901.

[18] R. Rosmaladewi, A. Abduh, and M. Basri, "English Lecturers' Experiences on Professional Development in Indonesian Polytechnics," Int. J. Lang. Educ., vol. 4, no. 2, pp. 314-321, 2020.

[19] Z. Rao and C. Lei, "Teaching English as a foreign language in Chinese universities: The present and future: An appropriate way to teach English in China is to balance teaching activities for elaborating linguistic details and developing students' communicative competence," English Today, vol. 30, no. 4, pp. 40-45, 2014.

[20] A. S. Rijal and A. M. J. Putri, "Determinants of English as language choice among Unaccompanied Migrant Children (UMC) in Makassar, Indonesia," Int. J. Humanit. Innov., vol. 2, no. 2, pp. 1-7, Apr. 2019, doi: 10.33750/ijhi.v2i2.36.

[21] D. Pecorari, "English as a Foreign Language (EFL) Versus English as a Second Language (ESL) Writing," in The TESOL Encyclopedia of English Language Teaching, John Wiley \& Sons, Inc., 2018.

[22] M. A. K. Halliday and R. Hasan, Cohesion in English. Routledge, 2014.

[23] W. Grabe and R. B. Kaplan, Theory and practice of writing: An applied linguistic perspective. Routledge, 2014.

[24] D. Ferris, "Promoting Grammar and Language Development in the Writing Class: Why, What, How, and When," in Teaching English Grammar to Speakers of Other Languages, Routledge, 2016, pp. 222-245.

[25] S. Bailey, Academic writing: A handbook for international students. Routledge, 2017.

[26] A. Khan, "Using films in the ESL classroom to improve communication skills of non-native learners," ELT Voices, vol. 5, no. 4, pp. 46-52, 2015. 
[27] H. Syam, M. Basri, A. Abduh, and A. A. Patak, "Hybrid e-Learning in Industrial Revolution 4.0 for Indonesia Higher Education," Int. J. Adv. Sci. Eng. Inf. Technol., vol. 9, no. 4, pp. 1183-1189, 2019.

[28] M. Henderson, N. Selwyn, and R. Aston, "What works and why? Student perceptions of 'useful'digital technology in university teaching and learning," Stud. High. Educ., vol. 42, no. 8, pp. 1567-1579, 2017.

[29] I. Iskandar, E. Basriana, and U. L. Mishina, "Language Styles of Advertising in Harper's Bazaar Magazine," GNOSI An Interdiscip. J. Hum. Theory Prax., vol. 3, no. 1, pp. 1-15, 2020

[30] F. Kerrigan, Film marketing. Routledge, 2017.

[31] J. R. Smith, D. Joshi, B. Huet, W. Hsu, and J. Cota, "Harnessing AI for Augmenting Creativity: Application to Movie Trailer Creation," in Proceedings of the 2017 ACM on Multimedia Conference, 2017, pp. 1799-1808.

[32] V. R. Ortega, "Spoof trailers, hyperlinked spectators \& the web," New Media Soc., vol. 16, no. 1, pp. 149-164, 2014.

[33] J. R. Fraenkel and N. E. Wallen, How to Design and Evaluate Research in Education. McGraw-Hill Higher Education, 2009.

[34] M. Cortazzi, Narrative analysis, vol. 12. Routledge, 2014.

[35] S. Greenberg, "The ethics of narrative: A return to the source," Journalism, vol. 15, no. 5, pp. 517-532, 2014, doi: $10.1177 / 1464884914523091$.

[36] H. D. Brown and P. Abeywickrama, Language assessment: principles and classroom practices. Pearson Education, 2010.

[37] P. R. Hinton, I. McMurray, and C. Brownlow, SPSS Explained. Routledge 2014.

[38] L. Stepanek, "A creative approach to language teaching. A way to recognise, encourage and appreciate students' contributions to language classes," in Creativity in the language classroom, 2015. [Online]. Available: https://www.teachingenglish.org.uk.

[39] Z. F. Miller and J. Maloney, "Review of language learning with digital video," About Lang. Learn. Technol., vol. 20 , no. 1 , pp. 46-49, 2016.

[40] A. Basari and R. A. Nugroho, "Subtitles for movie commercial trailers: A technology-based translation," in Application for Technology of Information and Communication (iSemantic), 2017, pp. 104-108.

[41] A. Abduh and R. Rosmaladewi, "Taking the Lextutor on-line tool to examine students' vocabulary level in business English students,” World Trans. Eng. Technol. Educ., vol. 15, no. 03, pp. 283-286, 2017.

[42] M. Rezaei and M. Jafari, "Investigating the levels, types, and causes of writing anxiety among Iranian EFL students: A mixed method design,” Procedia-Social Behav. Sci., vol. 98, pp. 1545-1554, 2014.

[43] S. T. S. Ahmed, B. T. A. Qasem, and S. V. Pawar, "Computer-assisted language instruction in South Yemeni context: a study of teachers' attitudes, ICT uses and challenges," Int. J. Lang. Educ., vol. 4, no. 1, pp. 59-73, 2020.

[44] N. P. L. Nariyati, S. Sudirman, and N. P. A. Pratiwi, "EFL Pre-Service Teachers' Perception toward the Use of Mobile Assisted Language Learning in Teaching English," Int. J. Lang. Educ., vol. 4, no. 1, pp. 38-47, 2020.

[45] I. Forsyth, Teaching and learning materials and the internet. Routledge, 2014.

[46] Muhammad, Hasbullah, Syarifudin, and A. A. Patak, "Implementation of English subject curriculum in Islamic secondary schools in Indonesia using Delphi method," XLinguae, vol. 12, no. 4, pp. 143-154, 2019, doi: 10.18355/XL.2019.12.04.12.

[47] H. Said and Z. H. Sidin, "Integrating Cross-Cultural Curriculum into School Based Curriculum: Using Peer Review Technique to Enhance Learners’ English Vocabulary," Sains Humanika, vol. 2, no. 4, 2014.

[48] J. Breddermann, J.-F. Martínez-Cerdá, and J. Torrent-Sellens, "A Model for Teacher Training to Improve Students' 21st Century Skills in Online and Blended Learning: An Approach from Film Education," in Optimizing K-12 Education through Online and Blended Learning. IGI Global, 2016.

[49] P. M. Greenfield, Mind and media: The effects of television, video games, and computers. Psychology Press, 2014.

[50] T. Chen, "The persuasive effectiveness of mini-films: Narrative transportation and fantasy proneness," J. Consum. Behav., vol. 14, no. 1, pp. 21-27, 2015.

[51] A. Abduh, M. Basri, S. Shafa, A. A. Patak, and R. Rosmaladewi, "Voices of English Department Students on Multicultural Values in an Indonesian Islamic Higher Education," Int. J. Lang. Educ., vol. 4, no. 3, pp. 459-468, 2020.

[52] A. A. Patak, S. Sahril, and M. B. Wello, "Exploring the cultural awareness of students majoring in English: a case study,” Int. J. Humanit. Innov., vol. 1, no. 4, pp. 11-19, Dec. 2018, doi: 10.33750/ijhi.v1i4.25. 